\title{
AN ITERATIVE APPROACH TO STRATEGIC PLANNING OF SOCIAL SERVICES AT REGIONAL LEVEL
}

\author{
Margarita Bogdanova ${ }^{1}$, Evelina Parashkevova ${ }^{2}$, Elitsa Lazarova ${ }^{3}$, Mariela Stoyanova ${ }^{4}$ \\ ${ }^{1}$ Professor, Ph.D., Tsenov Academy of Economics - Svishtov, Bulgaria, \\ m.bogdanova@uni-svishtov.bg \\ ${ }^{2}$ Associate Professor, Ph.D., Tsenov Academy of Economics - Svishtov, Bulgaria, \\ e.parashkevova@uni-svishtov.bg \\ ${ }^{3}$ Head Assistant Professor, Ph.D., Tsenov Academy of Economics - Svishtov, Bulgaria, \\ e.lazarova@uni-svishtov.bg \\ ${ }^{4}$ Assistant Professor, Ph.D., Tsenov Academy of Economics - Svishtov, Bulgaria, \\ m.stoyanova@uni-svishtov.bg
}

\begin{abstract}
The process of preparing documents for planning the development of the social sector in general and social services in particular is associated with a number of challenges. On the one hand, it is necessary to comply with standard normative and methodological regulations related to the preparation of a planning document. On the other hand, the dynamics of social needs resulting from changes in the environment require greater agile approach and proactivity of social policies and the documents regulating them. All this requires a fundamentally new approach to the creation and subsequent implementation of strategies for social services development.

The research problem of the study is the strategies for social services development in the Republic of Bulgaria at regional level and the research area is the approach to their creation. The main research thesis is that the application of an iterative approach to strategic planning of social services in the public sector is a tool for proactive policy, oriented to dynamically changing social needs in response to changes in the environment.

The iterative approach presents strategic planning process as separate steps that are constantly repeating, i.e. the approach is cyclical. This means that strategies for social services development, once established and consulted with stakeholders, are not finalized. They require active actions for their implementation, monitoring, updating, and reporting, which should be widely communicated not only at institutional, but also at sectoral and functional levels.

The aim of the scientific research is to present a fundamentally new for the public sector and for the social sphere conceptual approach to social services strategic planning, which will allow for an agile application of proactive behaviour.
\end{abstract}

Keywords: social services development strategies, iterative approach, strategic planning. 


\section{INTRODUCTION}

By 2020, Bulgaria's social policy has faced a number of challenges. The biggest one is dealing with the effects of the COVID-19 pandemic and taking proactive action. In this situation, the implementation of the entirely new Social Services Act has started, which will be supported by sub delegated legislation, i.e the Ordinance on the Quality of Social Services and the Ordinance on Social Services Planning, in which criteria for determining the services and the maximum number of users according to the number and the demographic profile of the population will be defined. The National Map of Social Services is expected to be an important document for social services planning. This is an entirely new organization of planning and managing social services, which should be based on good results and practices from previous periods and should also apply an entirely new model, which is expected to achieve a much higher degree of efficiency and effectiveness of the social policy in the field of services provided.

The social policy in Bulgaria suggests activity, i.e. actions in response to identified problems, adequate formulation, making sound decisions and implementing them, respectively. Given the importance of social policy and the influence of a wide range of direct and indirect stakeholders, it is important to organize the programming and strategic process.

\section{REVIEW OF THE LITERATURE ON STRATEGIC PLANNING OF SOCIAL SERVICES}

Strategic planning of social services is a priority issue in the policies of all governments. It involves decisionmaking in several important areas:

- The scope of interventions, i.e. social services to be subject of support, incl. through transfer of public funds.

- The degree of decentralization, which is closely linked to social service supply chains. In its most extreme form, the transfer of responsibility for social services is their privatization.

- Inter-institutional interaction. It is a function of the decisions on decentralization, the environment of providing social services, the applied tools for determining the needs for social services, etc.

These strategic issues are rather broad and address various aspects of the problem in the context of the political, macroeconomic and institutional environment in respective countries. For this reason, research with regard to social services planning is extremely fragmentary and it is difficult to derive working models and useful good practices that can be multiplied in another environment.

At the same time, social practice needs such models, as the cost of social services is a key tool for governments to redistribute income, and any decision that is not a subject of a thorough strategic analysis can have long-term negative consequences for all stakeholders.

\subsection{Coordination of social policies}

EU social policies are the responsibility of individual countries, and each country develops its own national legislative initiatives, including how to plan social services. However, in order to coordinate the social policies of the EU Member States, the so-called Open Method of Coordination (OMC) is applied. In principle, it is based on (EUR-Lex, 2020b):

- Collectively identifying and defining objectives to be achieved by all countries without being bound by them;

- Setting up measuring instruments (statistics, indicators, guidelines);

- Comparative analysis of the effectiveness of policies in individual EU countries in terms of employment, social protection, social inclusion, etc.

- Exchanging best practices.

An important part of the approach applied in the EU is the allocation of funds to achieve the objectives related to social services and social assistance (2020e). For instance, after the 2008-2013 crisis a Social Investment Package (SIP) was developed, which provides a framework for planning social services at local level based on person-centred approach, which combines prevention, early detection and intervention (European Commission, Directorate General for Employment, Social Affairs \& Inclusion, 2020c).

A European Social Network (ESN) of public sector organizations in the Member States providing similar services at local level is created in the EU to support the processes related to planning and implementing social services. 
ESN experts admit that there is no generally accepted definition of what social services planning is. They acknowledge that it includes mapping the needs of the population through data collection and aggregation, assessing data in order to target funding to areas or sectors of highest need, continuous monitoring and evaluation, and the involvement of multiple stakeholders. (Social planning at the local level, 2015).

The lack of a generally accepted definition of social service planning at regional level creates a broad framework of possibilities in terms of the objectives of the plans, the planning process, the monitoring and evaluation tools, the involvement of stakeholders, etc. Therefore, a variety of national and local practices exist in the EU, determined by the traditions of individual countries and regions, regulations, the needs of local communities and the capacity of local authorities.

While at national and supranational (EU) level social issues are rather subject to policies, at local level the focus is on strategic planning of programmes and specific social services.

\subsection{Good practices in analyzing the needs for services}

The collection and aggregation of data on the needs for social services and their mapping is carried out with the help of various technological platforms. In one of the municipalities in Tel Aviv, Israel, the mapping of the areas where the most vulnerable groups live is done through a geographic information system (GIS). Quantitative data on the social needs of the population are supplemented by qualitative surveys in the form of interviews and meetings to familiarize local authorities with the day-to-day challenges facing the vulnerable population. All information is integrated into the urban plan of the municipality and is used to take sustainable measures of long-term nature (Social planning at the local level, 2015).

A similar practice has been applied in South Australia (Maguire, 2014). The preparation for the use of a geographic information system (especially the creation of a database with the necessary information) takes more than 5 years. Currently, GIS is used for a wide range of analyses of social needs and the health status of employees, to develop models for housing reconstruction, needs assessment after major natural disasters and more. The Evidence Based Management Framework (EBMF) approach is applied, in which information is collected by participants in the process of providing social services, and the analysis of big data through GIS is the basis of decision-making processes.

Despite the importance of the Evidence Based Management Framework approach, it is not yet systematically applied in many countries (Liesl J.Zühlke at all., 2017). This creates a serious problem both in terms of the relevance of the services provided and their financial provision.

\subsection{Good practices in the process of social services planning}

Different practices are also observed in the social services planning processes. As a rule, the planning phases depend on the type of services and on the groups of users these services are intended for.

Two main planning models are most often used, namely project and cyclical planning. The first type is usually applied when introducing a new social service to the community. In general, the planning phases are as follows: needs assessment, implementing the service, monitoring and evaluating the effects, dissemination and exploitation.

Cyclical planning is applied when assessing the needs for already established services. This is the practice of the Vienna Department of Health Care and Social Welfare Planning. (Social planning at the local level, 2015). The planning model includes the following stages: data collection and monitoring; data management and evaluation; data analysis; synthesis report, plan, conception; discussion, negotiation and adoption; presentation; decision-making or implementation. The planning cycle is repeated over a period of time, for example every one or three years. However, the department has an annual budget of 150 thousand euros for these analyses, i.e. the process is financed from the municipal budget.

\subsection{Stakeholder participation}

Local authorities are aware of the importance of stakeholders for good planning. However, effective citizen participation is sometimes difficult to ensure. That is why various tools are used to motivate and engage people in planning social programmes and projects. They are as follows:

- Participatory backcasting method with the participation of stakeholders (A. Carlsson-Kanyamaa et all., 2008). It is used to build a scenario (vision and goals) for the future among participants and to define the steps to achieve the formulated goals. Thus, they are not only direct participants in the planning process, but also become problem-owners and seek solutions to the problem by approaching it responsibly and with dedication. 
- Logic model for programme planning and evaluation (Savaya, Waysman, 2005). It can schematically explain the logic of a programme to stakeholders, by visualizing the linkages among resources, activities, outcomes, indicators for them, etc. The model is useful in complex problem situations that need to be highlighted from different points of view to a non-professional audience. (Mccawley, 2001).

- Various technological solutions to help mediate contacts between people and organizations. In Stuttgart (Germany), citizen participation is facilitated by cross-generational meeting points and platforms, involving citizens and social organizations to discuss a range of social assistance issues (Social planning at the local level, 2015).

First, social service users should be able to participate in the planning process by providing feedback on key aspects of the plan.

Second, the participation of service providers in the planning process improves communication between them, provides a wider range of social services and avoids duplication of public efforts. Such a project was implemented in the Municipality of Györ, Hungary with the participation of representatives of the municipality, health facilities, social service providers (companies and NGOs), universities and colleges, police and others. (Social planning at the local level, 2015).

Social service planning tools vary both in their purpose and scope. Some are only suitable for a specific user group, while others are more universal.

Joint cooperation in planning and implementing social services is becoming increasingly necessary, especially during the Covid-19 pandemic. As in other sectors, technologies can be widely used, for example through online and mobile applications for virtual access to information centers, so that the process can be performed completely remotely.

In a broader sense, a complete reorganization of the work will probably be needed, which will include not so much and not only remote monitoring of the implementation of the planned services, but the application of intersectoral and interdepartmental approaches between service providers, municipal representatives, medical staff and others. In some cases, this means a complete redesign of service delivery processes, appropriate training, and the ability to deploy digital services and cloud-based platforms and tools. (ESN, 2020a).

A very useful tool would be pre-approved joint intervention protocols of the various institutions, as a coordinated response to challenges to be triggered at the first warning signs of an impending crisis. (ESN, 2020a).

In some cases, it is also necessary to change the regulatory framework, which is not fully adapted to these new approaches to service delivery.

\section{CRITICAL ANALYSIS OF THE PRACTICE OF SOCIAL SERVICES STRATEGIC PLANNING IN BULGARIA}

The social policy in Bulgaria traditionally faces various challenges. This situation has been exacerbated in recent months due to the entirely new conditions worldwide with regard to the consequences of the COVID19 pandemic. A number of social measures have been proposed as a tool to address some of the problems that have arisen in society. However, all of them are of a crisis and short-term nature, while long-term planning and outlining the path needed to improve the quality, delivery and effects of social services is key to a sustainable social policy.

In a similar environment, normative changes are undertaken in response to the various problems observed in the current practice of strategic planning of social services in Bulgaria. That is the reason why it is important that regulations in the new legal and regulatory framework unambiguously and adequately indicate the processes for planning and implementing public social policies.

Currently, in Bulgarian practices a number of weaknesses are observed in the planning of policies and strategies for the development of social services. For example, regional and municipal strategies for developing social services and the annual plans for implementing these strategies at municipal level regulate the specific measures and activities aiming to directly affect the target groups in the defined territorial unit. A standard approach to their preparation exists, although there are no methodological guidelines for this. Such standardization of the structural elements is found in the strategic documents of this type in the previous planning period (2001-2015), which on the one hand is a sign of continuity, but on the other hand can be an indicator of inheriting bad practices and lack of an update responding to changing needs.

Within a study of the quality of the regional strategies for social services, the research team identified some 
basic weaknesses, namely:

- With regard to the context in which the strategy is developed, omissions are identified in the formal presentation of a wide range of stakeholders involved in the development, without specifying their functions and responsibilities in the process. The creation and implementation of any public document requires close cooperation and discussion with civil society representatives to clarify a wider range of viewpoints and to include solutions that meet real needs. At first glance, in all strategies this principle is declaratively represented. However, it is not clear enough how they are attracted, what the method of selection is, and how they are involved in the process.

The Action Plan of the Strategy is based on needs analysis and assessment, which is based on statistical retrospective data related to the demographic picture, employment and unemployment, education, healthcare, housing policy, transport and connectivity. It is reasonable for the strategy and goal setting to further develop and improve the results already achieved and to be in line with clearly defined needs arising from the socio-economic profile of the territory where it will have an impact. An important factor is the expert capacity of the team preparing the analysis. In some cases, this task is assigned to intra-regional structures. However, external assignments are not an exception due to lack of institutional capacity. Properly and precisely defined needs of social groups are a key factor in developing adequate measures and activities for intervention and support.

- Strategy and organization of implementation - when defining the target regulation of strategic documents, a lack of knowledge about the foundations of strategic planning is traditionally observed. The vision is often incorrectly defined by including achievement tools. Priorities indicate the types of social services and do not outline priority areas for development. Most of the planned measures are rather concrete initiatives. These weaknesses, affecting the core of a strategic document, inevitably lead to deficits in implementing the activities and achieving the indicators.

Regarding the organization of the implementation, weaknesses are found in two main directions - in determining resource security for implementing the set activities and in the measures and indicators of achievement. The necessary financial, material resources, personnel capacity are often generally formulated without clear distinction between initial and target values, which threatens the achievement of the goals. The practice of defining indicators in the general case is to indicate end values, which are not always specific, without giving initial and intermediate ones. This impedes the periodic monitoring and control, which aims precisely to identify possible threats of non-compliance or delay and to have a timely impact.

- Management and coordination of strategy implementation - in terms of management and coordination of strategy implementation, problems such as unclearly defined functions and lack of traceability of coordination relations are also registered between the specified participants in the process. No explicit rules exist regarding how, when, and who will evaluate the results of the conducted social policy as well as what measures will be taken when determining negative or positive outcomes, respectively. These questions are extremely important and the answers are directing to the introduction of tools for correct and dynamic reporting on the results obtained from strategy implementation. A tendency is observed to involve a wide range of stakeholders and institutions in management and coordination structures, which has its negative effects, namely blurred responsibilities and difficult coordination. The lack of regular monitoring reports, for example, is a clear indicator of weaker control functions, despite those imposed on the Monitoring and Control Unit, a body listed in each regional strategy.

An important and mandatory element of the strategy is its communication programme. It is included in all regional strategies for developing social services. However, in most cases it includes general formulations of communication activity among all stakeholders and feedback from potential users.

The weaknesses described so far, mainly of strategic documents regarding planning the development of social services, are issues related to implementing strategic planning by institutions in Bulgaria as a whole that have been postponed over time. This is due both to the limited knowledge of some fundamental planning philosophies and to the frequently formal implementation of planning commitments without being clearly aware of the fact that it is an invariable and key prerequisite for the success of any public policy.

\section{CHANGES IN THE REGULATORY FRAMEWORK AND THE EXPECTED IMPACT ON THE STRATEGIC PLANNING PRACTICE OF SOCIAL SERVICES}

Current practices in Bulgaria for planning social services include the development of regional and municipal strategies for a five-year period and their subsequent specification in annual programmes for implementing the strategies at municipal level. This organization was implemented in two five-year planned cycles. At the end of the second cycle, in mid-2020, after nearly five years of discussion, a new Social Services Act (Social 
Services Act, 2020d) came into force. It defines a fundamentally new approach to planning, without regional strategies and a focus on the national needs and the annual municipal planning of the needs for similar services. It should be noted that the changes in the regulatory framework introduce a centralized approach to planning and analysis of needs as well as ways to meet them.

It is important to note that for the first time when developing the SSA, a joint Roadmap of the Working Group members and the Ministry of Labour and Social Policy was developed in advance, regulating in detail how public consultations, discussions and debates will take place and the principles and stages of the process. This is one of the prerequisites that the texts in the Act are the result of real debates with representatives of the civil society and different points of view are taken into account. It is the formal approach in public discussions and the involvement of all interested parties that is one of the main weaknesses in the development of strategic and planning documents in all public sectors in Bulgaria. It is expected that regulations, ordinances, tariffs, code of ethics and standards will be approved in order to support the Social Services Act. The Ordinance on the quality of social services, the Ordinance on social services planning and the National card for social services are of significant importance for the strategic planning process. The Ordinance on the quality of social services places strong emphasis on binding funding to the quality of services offered.

Coherence of individual planning documents at different levels is a step towards improving planning processes in the social sphere. For the first time the Social Services Act introduces the annual planning of social services for the whole country, which will be carried out on the basis of planning social services in municipal annual plans, in compliance with the priorities of the state policy in the field of social services under the Public Finance Act, and in accordance with the National Map of Social Services. On the basis of the municipal annual plans and the plans for the whole country, the annual planning of social services is carried out at national level, where social services are determined according to the National Map of Social Services and the number of their users as financing will be provided from the state budget within the calendar year.

The legislation also envisages institutional reform, namely the establishment of an Agency for the Quality of Social Services. It is important to study what methods and tools for quality control will be offered by the Ordinance, as so far there has been a formal reporting and weaker control over the implementation of public documents with a social focus. The definition of the criteria and conditions for determining and providing social services depending on the demographic profile of the population will be laid down in the Ordinance on planning social services. In order to ensure a planning process based on real knowledge of local needs, a National Map of Social Services will be created, which is part of an entirely new approach aiming to overcome significant gaps in this regard. It is expected that the development of this map will improve access to social services and support the integrated and coordinated supply of such.

Promoting public-private partnerships and assigning social service providers by municipalities is a key point in the Social Services Act. It is expected that this will improve both the scope and the quality of services provided.

Although the Social Services Act refers to the Regulations for its implementation in the part concerning planning, the draft of the latter does not include texts related to the annual planning of social services at municipal and national level (Council of Ministers, 2020). This raises doubts about the existence of a clear vision of how exactly the planning provided in the Act will be organized and coordinated and is a prerequisite for chaos in planning when preparing the new strategic documents in the field of social services in Bulgaria.

\section{CONCEPTUAL ITERATIVE APPROACH TO STRATEGIC PLANNING OF SOCIAL SERVICES}

Formal strategic planning is rational in terms of stages, phases and actions taken for its implementation. Traditionally, senior management determines development policies, and middle management prepares a plan of activities and tasks to achieve the goals (Grant, 1991). This continuous cyclical process of strategic planning includes the development of a vision, mission, goals, and analysis of the internal and external environment, definition of alternative strategies, and definition of strategic alternatives, implementation of the strategy and monitoring and control over its implementation. Thus, high-level policy becomes concrete at middle management levels (Johnsen, 2019). This traditional approach has its limitations, as formality replaces creativity in planning. Efficiency increases only when formal strategic planning encourages innovative approaches and flexibility in implementation (Dibrell, Craigb, \& Neubaumc, 2014). This means that planning systems must allow iterations to adapt to changes in the environment and the needs of stakeholders.

Current practices of public services strategic planning show a number of weaknesses, such as static 
documents, difficult adaptation to needs, implementation constraints arising in the course of implementation, which did not exist when preparing relevant strategies, programmes and plans needed for strategy implementation. All this, together with the chronic lack of expertise in logical relations, approaches, methods and techniques in strategic planning, necessitates the search for a new, perhaps simpler approach to strategic planning of sectoral policies and strategies. A strategic change in planning approaches is needed, which do not determine and formalize the process, but provide an opportunity for rapid response to measures and actions in the event of a change in the environment and needs.

Content analysis of strategic planning documents shows that they differ significantly. Some are specific with a high degree of detail, based on a top-down approach, issued as an implementation directive. Others are based on a bottom-up approach, with broad involvement of interested parties and lessons learned from experience. Regardless of the applied approach to strategic planning, the need for flexible implementation management comes to the fore. "All strategies must be adaptable, with rapid feedback and effective information flows, in order to respond to new information and to take account of changing circumstances or unexpected events." (Council of Ministers, Strategic Planning and Management Directorate, 2007).

In the process of strategic planning, six indicative stages can be distinguished, which are ongoing and form a cyclical process (see Fig. 1).

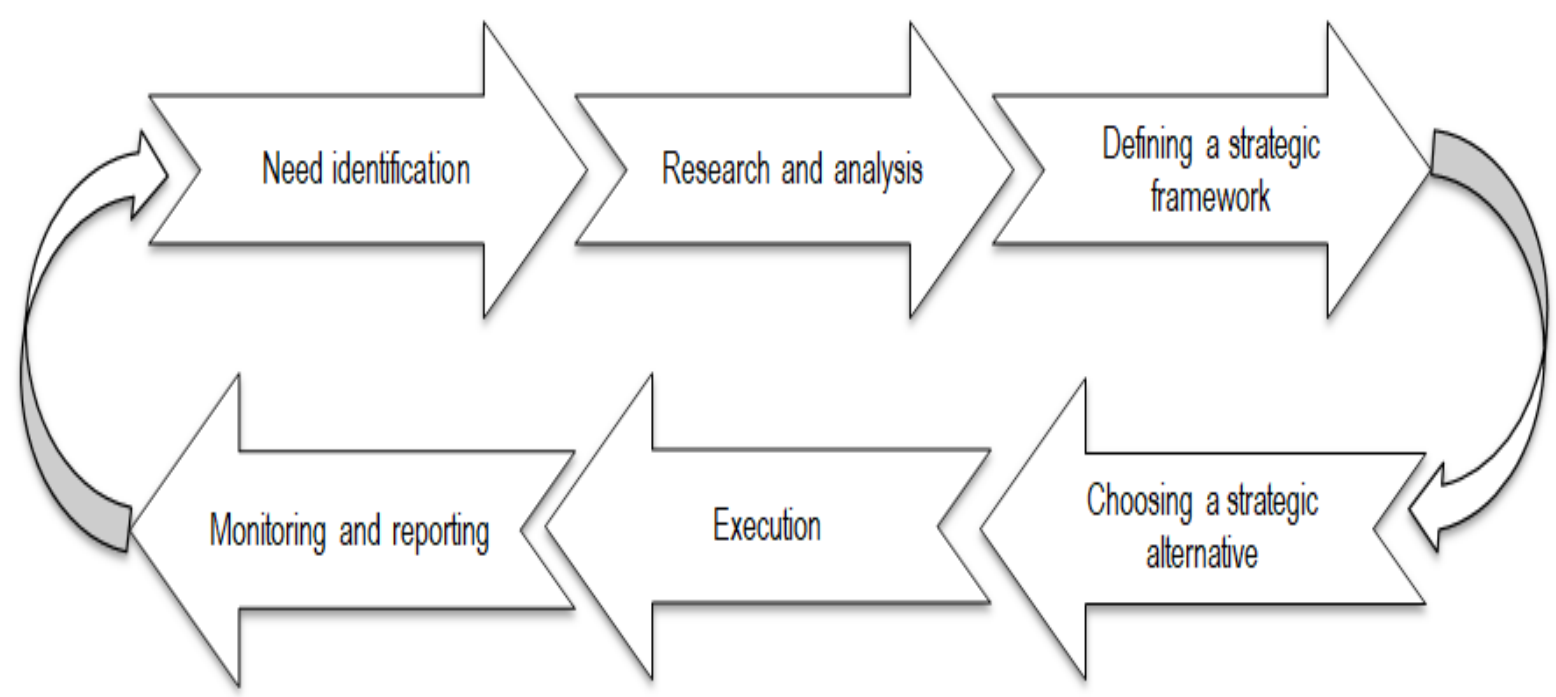

Fig. 1. Stages of a conceptual iterative model for strategic planning of social services

This model focuses on the implementation of tasks at each stage, which allow for adaptability and feedback from interested parties and users of social services. It allows continuous iterations back and forth in order to check the adequacy and effectiveness and adjust measures, actions, goals according to changes in the environment and needs. Achieving a similar approach is possible by clear definition of the actions and tasks performed at each stage of the model and the availability of control questions to verify key parameters of the strategy.

The application of this model requires good normative and methodological preparation, as documents of similar nature are the input to the application of the model. Whether it is a national roadmap, a national strategy or a concept for the development of social services, it is necessary to go through each stage of an iterative model of strategic planning with a high degree of adaptability and coordination with interested parties.

Without dwelling on the main activities and tasks which form the overall procedure for implementing a conceptual iterative model for strategic planning of social services, we will focus on the control questions that must be asked at each stage. 
Table 1. Control questions when implementing a conceptual iterative model for strategic planning of social services

\begin{tabular}{|c|c|}
\hline Stage & Control questions \\
\hline $\begin{array}{c}\text { Need } \\
\text { identification }\end{array}$ & $\begin{array}{l}\text { 1. Have the identified needs existed before and how have they been intervened? } \\
\text { 2. Are the identified needs real? } \\
\text { 3. Is it possible these needs to be met by the respective administration? } \\
\text { 4. What are the main factors for the emergence of the needs? } \\
\text { 5. How is broad stakeholder involvement in identifying needs ensured? } \\
\text { 6. Is it necessary to review the existing measures in relation to identified needs? }\end{array}$ \\
\hline $\begin{array}{l}\text { Research and } \\
\text { analysis }\end{array}$ & $\begin{array}{l}\text { 1. Is the information about needs up-to-date, sufficient and complete? } \\
\text { 2. Does the information make it possible to outline trends in perspective? } \\
\text { 3. Is it possible to predict future states of identified needs? } \\
\text { 4. Does the analysis bring out key factors, levers of influence and solutions to } \\
\text { identified problems? } \\
\text { 5. Is sufficient quantity and quality information provided to interested parties and } \\
\text { representatives of the separate groups of service users? } \\
\text { 6. Are the findings real? }\end{array}$ \\
\hline $\begin{array}{l}\text { Defining a } \\
\text { strategic } \\
\text { framework }\end{array}$ & $\begin{array}{l}\text { 1. Do the defined vision, mission, goals, priorities, directions, measures, projects / } \\
\text { activities meet the diagnosed needs? } \\
\text { 2. Are measurement indicators defined? } \\
\text { 3. Are the necessary resources defined - in the respective types and quantities? } \\
\text { 4. Are resources identified? } \\
\text { 5. Have strategic alternatives been developed? } \\
\text { 6. Has an assessment been made of the possible impacts of the different alternatives? } \\
\text { 7. Is participation ensured and are the interested parties and the representatives of the } \\
\text { different groups of service users informed about the alternatives defined and their } \\
\text { impact? }\end{array}$ \\
\hline $\begin{array}{l}\text { Choosing a } \\
\text { strategic } \\
\text { alternative }\end{array}$ & $\begin{array}{l}\text { 1. Are specific criteria for choosing an alternative defined? } \\
\text { 2. Is the choice justified? } \\
\text { 3. Is the choice based on consensus between institutions involved, interested parties, } \\
\text { representatives of different consumer groups and service providers? } \\
\text { 4. Is the choice informed? } \\
\text { 5. Does the choice allow for flexibility in implementation? } \\
\text { 6. Is the resource (tangible and intangible) provision of the implementation of the } \\
\text { chosen strategic alternative possible? }\end{array}$ \\
\hline Execution & $\begin{array}{l}\text { 1. Has a working organization been established to implement the chosen strategic } \\
\text { alternative? } \\
\text { 2. Are the institutions, interested parties, representatives of individual consumer } \\
\text { groups and service providers really involved in the implementation process? } \\
\text { 3. Are the necessary tangible and intangible resources provided? } \\
\text { 4. Are the planned deadlines in the implementation kept? } \\
\text { 5. Are the planned results achieved? } \\
\text { 6. Is it necessary to review, refine, and update the chosen strategic alternative? }\end{array}$ \\
\hline $\begin{array}{l}\text { Monitoring and } \\
\text { reporting }\end{array}$ & $\begin{array}{l}\text { 1. Has organization been created to monitor the implementation of the strategy on an } \\
\text { ongoing basis? } \\
\text { 2. Is the monitoring process documented? } \\
\text { 3. Is there a flexible system for progress reporting? } \\
\text { 4. Is it possible to take corrective actions in the short term? } \\
\text { 5. Is publicity of the results ensured and are stakeholders involved in the monitoring } \\
\text { process? } \\
6 \text {. Is there a smooth mechanism for adequate change in the chosen alternative in case } \\
\text { of changes in needs or deviations from the set indicators? }\end{array}$ \\
\hline
\end{tabular}

These questions can be designed as a checklist for each stage of the model implementation or can be integrated into the strategic planning process and run in parallel with it. Regardless of the approach chosen, these questions aim to identify possible omissions or weaknesses that need to be addressed in a timely and adequate manner, i.e. thus providing flexibility in compliance with quality assurance standards of a strategy for the development of social services. 


\section{DISCUSSION}

Issues related to strategic planning are again in the focus of scientific research. After years of favoritism and subsequent rejection, the strategic planning process shows the need to seek innovative, flexible solutions in response to pressing social problems. The search for new approaches involves avoiding existing cumbersome procedures burdened with bureaucratic practices, voluminous documentation and complex coordination. The emphasis is on the possibilities for a flexible ongoing process, allowing for rapid adaptation of the planning document to changes in the environment, the interests of the parties involved, the needs of the beneficiaries of social services.

The implementation of practices for mapping the needs and the provision of social services, their clustering and individualization are mechanisms for implementing working public policies, which can preventively apply measures to minimize the number and scope of risk groups that are also users of social services. The aim is to replace the currently applied advanced management approach with a proactive one, which will be able to react in advance to the changes in public life and future challenges to social services. The very planning, and especially strategic planning, is a long and complex process that cannot identify problems and offer solutions in a short time. Yet social needs cannot be postponed. This requires proactivity of the developed strategic decisions, i.e. anticipating future needs today and offering adequate solutions now.

\section{REFERENCE LIST}

A. Carlsson-Kanyamaa et all. (2008). Participative backcasting: A tool for involving stakeholders in local sustainability planning. Futures 40 , pp. 34-46.

Council of Ministers. (2020). Proekt na Postanovlenie na Ministerski savet za priemane na Pravilnik za prilagane na Zakona za sotsialnite uslugi. Sofia.

Council of Ministers, Strategic Planning and Management Directorate. (2007). Formulirane na politiki i razrabotvane na strategii. Manual. Sofia.

Dibrell, C., Craigb, J., \& Neubaumc, D. (2014). Linking the formal strategic planning process, planning flexibility, and innovativeness to firm performance. Journal of Business Research, 67 (9), 2000-2007.

ESN. (2020a). Covid-19 impact on social services: Lessons learnt and planning forward. Downloaded from http://www.esn-eu.org/sites/default/files/2020-07/Covid-

19\%20impact\%20on\%20social\%20services\%20Lessons\%20learnt\%20and\%20planning\%20forward\% 20briefing_0.pdf

EUR-Lex. (n. d.). (2020b). Downloaded from Open Method of Coordination: https://eurlex.europa.eu/summary/glossary/open_method_coordination.html?locale=bg, 2020.

European Commission, Directorate General for Employment, Social Affairs \& Inclusion . (n. d.). (2020c). Downloaded from Policies and Activities, Social investment: http://ec.europa.eu/social/main.jsp?catld=1044\&langld=en.

Grant, R. (1991). The Resource-Based Theory of Competitive Advantage: Implications for Strategy Formulation. California Management Review, 30 (3), pp.114-135.

Johnsen, A. (2019). Does formal strategic planning matter? An analysis of strategic management and perceived usefulness in Norwegian municipalities. International Review of Administrative Sciences.

Liesl J.Zühlke at all. (2017). A Comprehensive Needs Assessment Tool for Planning RHD Control Programs in Limited Resource Settings. Global Heart, Volume 12, Issue 1, 2017, pp. 25-31.

Maguire, G. (2014a). GIS Clarifies the Big Picture, Helps People in Need. Downloaded from Social Services Planning Streamlined: https://www.esri.com/about/newsroom/arcnews/social-services-planningstreamlined/

Mccawley, P. (2001). The Logic Model for Program Planning and Evaluation. Downloaded from https://www.researchgate.net/publication/237568681_The_Logic_Model_for_Program_Planning_and_ Evaluation

Savaya, Riki, Mark Waysman. (2005). The Logic Model. Administration in Social Work, 29:2, 85-103, DOI: 10.1300/J147v29n02_06. 
Social planning at the local level. (2015). Downloaded from European Social Network: https://www.esneu.org/sites/default/files/publications/ESN_Social_planning_at_the_local_level.pdf

Social Services Act. Sofia: Prom. (2020d). SG, issue.24/ $22^{\text {nd }}$ March 2019, am. SG issue $101 / 27^{\text {th }}$ December 2019, am. SG, issue 65/21 ${ }^{\text {st }}$ July 2020, am. and suppl. SG, issue $71 / 11^{\text {th }}$ August 2020.

Social Assistance Act. Prom. (2020e). SG, issue 56/19 $9^{\text {th }}$ May 1998, last am. SG, issue $71 / 11^{\text {th }}$ August 2020. 